\title{
El espacio público como soporte reivindicativo y las estrategias para reclamar el patrimonio colectivo: el caso de la plaza Taksim en Estambul
}

Francisco Javier Navarro de Pablos | investigador del Dpto. de Promoción y Difusión de la Subdirección General de Arquitectura, Vivienda y Suelo del Ministerio de Fomento

URL de la contribución <www.iaph.es/revistaph/index.php/revistaph/article/view/3815>

El espacio público es uno de los ventrículos de la ciudad: el motor que filtra las relaciones sociales entre los ciudadanos que la habitan, capaz de contraer o dilatar la secuencia espacial dentro de la ciudad contemporánea. Como parte inherente de la sociedad, evoluciona siguiendo el ritmo que el comportamiento colectivo va dictando, formándose una relación de dependencia vital.

En multitud de casos a lo largo de la historia y espacio, la plaza, ese ágora social, ha sido vía de escape para reivindicaciones y manifestaciones sociales, políticas y culturales. Siendo un fenómeno en alza se antoja innegable la necesidad de analizar qué parámetros urbanos, espaciales, arquitectónicos y socieconómicos perfilan el contexto de las reivindicaciones y su relación con estos "lugares-altavoz". La concentración de estos movimientos en los centros urbanos e históricos de las ciudades configura uno de los retos más importantes que tienen ante sí las administraciones públicas.

Desde la plaza de Mayo de Buenos Aires y sus madres o las fugaces pero cruciales protestas en la plaza de Tian'anmen, a las mediáticas y masivas de la Puerta del Sol, surgen dos sentencias irrefutables: la desactualización de los mecanismos de participación ciudadana en la configuración de la ciudad y la conservación del patrimonio y la incidencia directa de la atmósfera socio-política en la manera de ocupar el espacio. Cada fenómeno reivindicativo guarda unas singularidades que lo hacen paradigmático: el movimiento surgido en Estambul en torno al parque Gezi y su anexa plaza Taksim encarna el primer manifiesto ecologista contra un modelo de patrimonio desfasado y autoritario. La ciudadanía es consciente de la existencia de un patrimonio ecológico en peligro y cree en su capacidad de intervenir como actriz principal del proceso.

En 2001, Recep Tayyip Erdogan, ex-alcalde de Estambul, funda el Partido de la Justicia y el Desarrollo (AKP). Sólo dos años después se convierte en primer ministro y comienza un profundo proceso de reforma económica y una política exterior aperturista y cercana a la Unión Europea. Sin embargo, 2011 supone un doble punto de inflexión: con las revoluciones árabes, la retórica conservadora y religiosa del primer ministro empieza a extremarse mientras el desarrollo económico se frena.

Esta estrategia disuasoria muestra su fuerza y Erdogan comienza a controlar el poder judicial, centraliza el poder del partido y silencia a los principales medios de comunicación interviniendo directamente sobre las líneas editoriales. La aprobación de una reforma educativa a favor de la introducción de elementos islámicos en la enseñanza, la limitación del consumo del alcohol, la prohibición total del aborto o la oposición a la comunidad LGTB acaban por desatar un descontento generalizado en la sociedad turca. Esta nublosa atmósfera de límites civiles desdibujados e incipientes abusos lleva al progresivo distanciamiento entre poder civil y político, raíz de toda revolución.

El gobierno de Erdogan, saltándose a las autoridades locales, diseña un proyecto de reforma para la plaza Taksim y el parque Gezi, en el que además de una importante reducción de zonas verdes, se plantea la reconstrucción del antiguo cuartel otomano para la creación de un nuevo centro comercial y la edificación de una nueva mezquita. El proyecto busca enfatizar una supuesta 


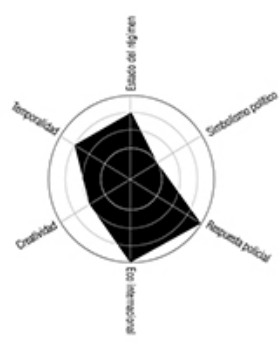

Parámetros político-sociales

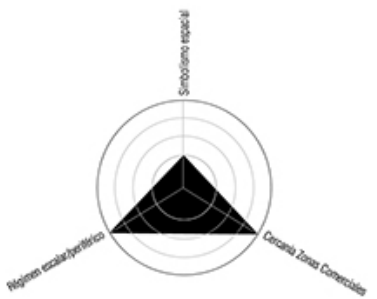

Parámetros de contorno urbano

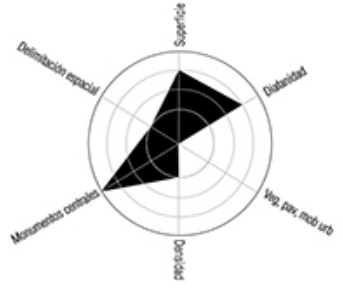

Parámetros espaciales

Parámetros político-sociales (temporalidad, estado de régimen, simbolismo político, respuesta policial, eco internacional, creatividad): gobierno autoritario pero estable, discutido por crisis y polémicas asociadas a la corruptela, radicalización religiosa y mala gestión de los recursos, enfrentado a una sociedad que apuesta por una mirada europea, laica y contemporánea. Como se concluye, una fuerte represión policial conlleva una posterior internacionalización del conflicto, lo que suele desembocar en más presión para el gobierno implicado. Sin tratarse de un espacio representativo de poder, Taksim se convierte en símbolo; la perversión de un espacio público en un Estado con derechos civiles cercenados supone en sí un triunfo, sin necesidad de recurrir a fórmulas creativas que visibilicen las proclamas.

Parámetros de contorno urbano (simbolismo espacial, cercanía zonas comerciales, régimen escalar periférico): crucial presencia de actividades comerciales generadoras de flujos y realidad cotidiana, convirtiéndola en un lugar totalmente accesible y considerado como colectivo, conocido y recorrido por la ciudadanía. La cercanía del parque Gezi también provoca una continuidad y conexión con uno de los pocos espacios verdes de la ciudad. A modo de alfombra, el pavimento parece extenderse desde el parque a las fachadas que enmarcan la plaza, pero con tres barreras de tráfico rodado que impiden una lectura unitaria del espacio. Se trata, además, de un espacio con capacidad para formar parte de un régimen escalar de repetición, una caja de resonancia en el que las protestas se expanden, guardando estrecha relación con la existencia de las redes sociales, que constituyen la herramienta más útil para la propia protección de los manifestantes.

Parámetros espaciales (delimitación espacial, superficie, diafanidad, veg. pav. mob urb., densidad, monumentos centrales): centralidad de un hito/monumento y la obvia presencia del parque reclamado hacen de Taksim un espacio diáfano tensionado entre dos focos pero con una gran capacidad de acogida. La escasa presencia de mobiliario urbano y nula de vegetación, permiten que en las sucesivas protestas desarrolladas los manifestantes sientan y den una perspectiva de unidad. Frente al parque Gezi, una "isla" peatonal acoge las paradas de metro y autobús a modo de intercambiador residual, con escaso interés y sin continuidad peatonal con el elemento circular más elevado. Aunque este último hito urbano es el que concentra las primeras concentraciones, es en las propias puertas del parque donde se desarrollan mayores incidentes y disturbios.

Imágenes procedentes del trabajo de investigación Espacio público como soporte reivindicativo: la ciudad participada, desarrollado por el autor entre 2014 y 2015, en el Departamento de Urbanismo y Ordenación del Territorio, de la Escuela Técnica Superior de Arquitectura de Sevilla, con la supervisión de María Teresa Pérez Cano y dentro del Grupo de Investigación HUM-700 | gráficos Francisco Javier Navarro de Pablos

modernización impulsada por el gobierno, a la vez que rememorar el pasado imperial de Turquía y sus lazos religiosos con el Islam; el significado de Taksim como espacio libre, laico y asociado a movimientos ecologistas por su cercanía al parque Gezi se ven obviados.

El 28 de mayo de 2013, representantes de un recién creado movimiento pro-Gezi, se instalan en Taksim para evitar la destrucción del parque. Poco después se unen manifestantes de diversos colectivos y ciudadanos de a pie. Cuando se distribuyen las imágenes de la respuesta policial contra las concentraciones pacíficas de los ecologistas, la congregación de manifestantes crece exponencialmente. Al mismo tiempo que la protesta se "universaliza", el espacio virtual gana terreno al siempre imprescindible mapa físico. Si se pretendiese reducir el fenómeno de Taksim a su consideración como conflicto de carácter ecologista se estaría dejando de lado su objetivo de fondo, el de rebatir un modelo de gobierno y recuperar una parte del patrimonio colectivo urbano. 


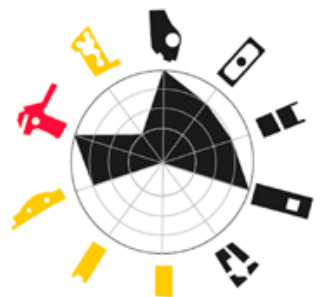

Represión militar-policial versus no intervención

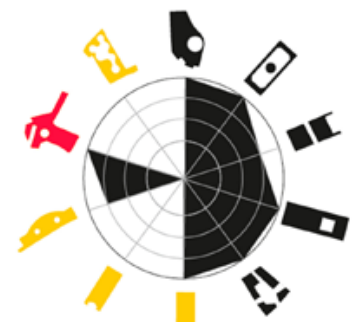

Presión internacional versus visibilidad local del conflicto
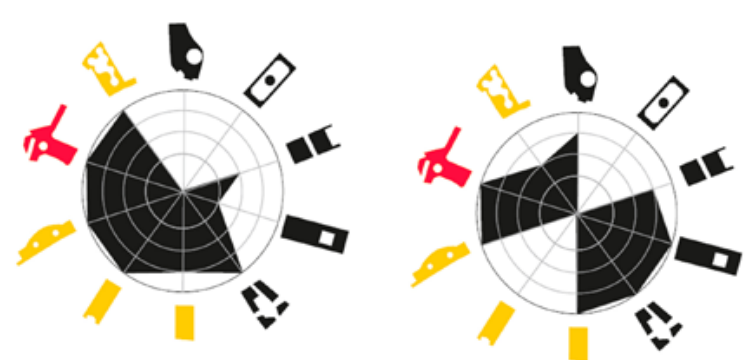

Cercanía a zona comercial versus zonas desactivadas de actividad mercantil
Capacidad de expansión-imitación en otros lugares versus nulo régimen escalar

Representación de la planta de las plazas estudiadas para un análisis comparativo con la plaza Taksim, de rojo. En amarillo las pertenecientes a regímenes democráticos y en negro los dictatoriales. En sentido horario, tras Taksim, plaza de la Encarnación (Sevilla), Tahrir (El Cairo), plaza de Mayo (Buenos Aires), plaza de la Moneda (Santiago de Chile), Tian'anmen (Pekín), Alexander Platz (Berlín), Zuccotti Park (Wall Street, Nueva York), plaza de la Paz (Barranquilla) y Puerta del Sol (Madrid).

Parámetros de tensión: represión militar-policial versus no intervención. Taksim comparte niveles de represión con Tahrir y Tian'anmen, dos de las protestas con mayor repercusión internacional, siendo la única de los estados democráticos. La fuerte respuesta político-militar del conflicto correspondería a dictaduras que (excepto en el caso de las abuelas y madres bonaerenses, cuyo tratamiento partía de una visión paternalista del colectivo por parte de Videla), desencadenan detenciones y ejecuciones. Cuatro muertos -presentados como efectos colaterales y de difusa autoría-y multitud de heridos trazan una atmósfera alejada de las originales manifestaciones pacíficas que conquistan Taksim; como consecuencia directa se difumina el objetivo de luchar y ocupar el espacio público para proteger el patrimonio ecológico de la ciudad. Ese salto de perspectivas, imagen y difusión de las protestas viene dado por dos elementos: la inclusión de colectivos politemáticos y la contundencia policial. Esta última emerge como sujeto principal y alienta la participación empática de la mayoría del poder civil.

Parámetros de tensión: presión internacional versus visibilidad local del conflicto. La repetida correspondencia entre una fuerte respuesta militar y una internacionalización del conflicto se hace evidente con el estudio del impacto político y periodístico de cada caso. En el caso de las dictaduras, el patrimonio del poder es el propio espacio público: el mero hecho de su ocupación ya es valorado internacionalmente como un logro democrático. Para el Partido Comunista Tiananmen es un lugar sagrado, junto a la Ciudad Prohibida, el último lugar imaginado como espacio de disputa. El poder simbólico de Taksim dista del caso pekinés, aunque guarda ciertas similitudes con el parque de Zuccotti de Nueva York: espacios urbanos secundarios que consiguen marcan un sello singular. La manifestación revaloriza la plaza y la carga de simbología.

Parámetros de tensión: cercanía a zona comercial versus zonas desactivadas de actividad mercantil. Siendo los lugares cercanos a áreas comerciales puntos "calientes" en el desarrollo de ocupaciones espaciales, por cercanía, actividad, conocimiento, accesibilidad y posible fuente de recursos, en la mayoría de casos las manifestaciones acaban uniendo las zonas ocupadas con las comerciales, como en un ritual casi primitivo, suponiendo el corte de calles y convirtiendo un derecho fundamental de ocupar y protestar la ciudad en un hecho de alteración de un orden público que no es público si no privado e individualista. Las democracias, sistemas proclives a la autorización de concentraciones de mayor envergadura, con una libertad de movimiento ampliada y sistema mercantil liberalizado, las zonas comerciales parecen tener mayor incidencia en la elección de los espacios de protesta. Parece claro que la concepción de la ciudad como espacio colectivo está asociada a la convivencia en tiempo y espacio de multitud de usos. En la ciudad contemporánea, como ente heterogéneo, la actividad comercial es fuente de vida urbana. El frenético panorama cotidiano de Taksim quedaría desactivado si su fuente principal de ocupación fuera un uso residencial elevado. Aunque este último hito urbano es el que concentra las primeras concentraciones, es en las propias puertas del parque donde se desarrollan mayores incidentes y disturbios.

Parámetros de tensión: capacidad de expansión-imitación en otros lugares versus nulo régimen escalar. Detectar la intensidad de la resonancia de las protestas en otras partes del mundo y la reacción ante las mismas permite cartografiar un estado del espacio público en todo el mundo, desde un gesto tan concreto como las manifestaciones de Taksim. En contra de cómo se manifestó gran parte de la prensa internacional, Taksim no tiene lazos de unión -desde el punto de vista social- con la Primavera Árabe. Lo que caracteriza a la lucha en Taksim es que no se puede reducir a un conflicto de carácter puramente ecologista o protector de los espacios libres: es una lucha por un modelo de Estado y por el significado del espacio público. Es por su carácter transversal por lo que es capaz de saltar a otros lugares, hacerse imitable. Con esa capacidad de albergar protestas, se expanden por el territorio turco y la propia ciudad. Con un gran efecto amplificador, los ecos llegan a Alemania, donde ciudadanos de origen turco y simpatizantes se manifestaron por las calles del Kreuzberg de Berlín como apoyo a sus compatriotas concentrados. Taksim pasa de ser un área urbana específica a transformarse en una realidad compleja e independiente -en la medida de lo posible- del espacio físico y es capaz de extenderse por el mundo. 
Es aquí donde radica su singularidad: es la lucha por un espacio público como sujeto de la protesta.

El proceso global del neo-liberalismo, modelo referente para Erdogan en sus primeros mandatos, supone el desmantelamiento de un estado del bienestar en ocasiones ya perjudicado, y en el campo patrimonial, la transición paulatina de la toma de decisiones del estado hacia los promotores privados (RICART; REMESAR, 2013).

El escenario público ha sido usurpado por la "escena psíquica" privada en detrimento tanto del individuo como de la sociedad (SENNET, 1974), priorizando los valores de la "esfera privada" frente a aquellos inherentes a la esfera pública (BOYER, 1994). Siendo innegable la deriva de una esfera pública absorbida por imparables procesos de privatización, aparecen motivos de esperanza como la reconquista de espacios públicos coincidiendo con épocas de crisis y cambios globales. Tomadas como oportunidad, estos procesos de permuta socioeconómica sirven para reinventar la manera de hacer ciudad, habitarla y ocuparla. En Taksim vemos claros indicios de un interés colectivo por reclamar esos espacios como comunes y patrimoniales. La creatividad en las fórmulas de manifestación hace pensar que una realidad alternativa puede consolidar la base de una nueva "ciudad participada" (SHEPPARD, 2012).

La conquista de lo público por parte del colectivo supone la confirmación de que el espacio público urbano es el primer y último refugio civil en periodos convulsos. El derecho a ocuparlo, discutirlo, transgredirlo, transformarlo y, en definitiva, considerarlo patrimonio común de un determinado colectivo es universal e independiente a cualquier régimen, realidad espacial o contexto urbano. Cuando el acceso a ese espacio público está acotado a un determinado colectivo se acaba convirtiendo en el blanco perfecto para la "apropiación simbólica" (TEJERINA, 2005). El éxito de esta ocupación vendrá marcada por la capacidad popular de contestación, de producción de nuevos lugares e identidades asociadas a espacios públicos y de la relectura del paisaje urbano a través del compromiso con la justicia social.

\section{BIBLIOGRAFÍA}

- RICART, N; REMESAR, A. (2013) On the waterfront: Reflexiones sobre el Espacio Público. The online magazine on Waterfronts, Public Space, Urban Design and Public Art [en línea], vol. 25, 2013, pp. 5-35 <http://www.ub.edu/escult/ Water/w-25/onthewaterfront_25.pdf> [Consulta: 04/03/2014]

- BOYER, CH. (1994) The City of Collective Memory. Cambridge: MIT Press, 1994

- SENNETT, R. (1974) El declive del hombre público. Barcelona: Anagrama, 2011, pp. 16-24

- SHEPPARD, B. (2012) Lo que revela Occupy Wall Street. Viento Sur, n. ${ }^{\circ} 120,2012$

- TEJeRINA, B. (2005) Movimientos sociales, espacio público y ciudadanía: Los caminos de la utopía. Revista Crítica de Ciências Sociais, n. ${ }^{\circ}$ 72, 2005, pp. 67-97 